\title{
In Situ Fabrication and Repair (ISFR) Technologies; New Challenges for Exploration
}

\author{
Julie A. Bassler", Melanie P. Bodiford ${ }^{\dagger}$, Monica S. Hammond ${ }^{\ddagger}$, Ron King ${ }^{\S}$, Carole A. Mclemore ${ }^{* *}$ \\ NASA/Marshall Space Flight Center, Huntsville, AL, 35812 \\ Nancy R. Hall ${ }^{\dagger \dagger}$ \\ NASA/Glenn Research Center, Cleveland, OH, 44135 \\ Michael R. Fiske ${ }^{\ddagger \ddagger}$ \\ Jacobs Sverdrup, Huntsville, AL 35806 \\ and \\ Julie A. Ray ${ }^{\S \S}$ \\ Teledyne Brown Engineering, Huntsville, AL, 35807
}

\begin{abstract}
NASA's human exploration initiative poses great opportunity and great risk for manned missions to the Moon and Mars. Engineers and Scientists at the Marshall Space Flight Center (MSFC) are continuing to evaluate current technologies for in situ resource-based exploration fabrication and repair applications. Several technologies to be addressed in this paper have technology readiness levels (TRLs) that are currently mature enough to pursue for exploration purposes. However, while many technologies offer promising applications, these technologies must be pulled along by the demands and applications of this great initiative. The In Situ Fabrication and Repair (ISFR) Element will supply and push state of the art technologies for applications such as habitat structure development, in situ resource utilization for tool and part fabrication, and repair and non-destructive evaluation (NDE) of common life support elements. As an overview of the ISFR Element, this paper will address rapid prototyping technologies, their applications, challenges, and near term advancements. This paper will also discuss the anticipated need to utilize in situ resources to produce replacement parts and fabricate repairs to vehicles, habitats, life support and quality of life elements. Overcoming the challenges of ISFR development will provide the Exploration initiative with state of the art technologies that reduce risk, and enhance supportability.
\end{abstract}

\section{Introduction}

The In Situ Fabrication and Repair (ISFR) Element was defined by the Office of Biological and Physical Research (OBPR) in response to the Human Support Systems (HSS) Program. The ISFR Element is managed as a technology and hardware development program at the Marshall Space Flight Center (MSFC) in Huntsville, Alabama. The ISFR

\footnotetext{
* Element Lead, Technology \& Capability Development Projects Office/SY10

${ }^{\dagger}$ Habitat Structures Project Manager, Technology \& Capability Development Projects Office/SY10

‡Fabrication Technologies Project Manager, Technology \& Capability Development Projects Office/SY10

${ }^{\S}$ Repair \& NDE Technologies Project Manager, Technology \& Capability Development Projects Office/SY10

** Activity Lead, Technology \& Capability Development Projects Office/SY10

${ }^{\dagger \dagger}$ Product Line Lead, Glenn Research Center/RUF, AIAA Sr. Member

\# Habitat/Structures Chief Technologist, NASA/MSFC/SY10, AIAA Sr. Member

$\S$ ISFR Element Engineer, NASA/MSFC/SY10, AIAA Member
} 
Element has the mission to provide a necessary function of fabrication and repair of equipment and materials at the location where the equipment is operating, i.e., in situ. The scope of this activity includes all mechanical and electrical components and assemblies to progress technologically in a phased approach to meet the increasing scope of the Exploration Initiative. The scope of this effort includes the development of supporting fabrication, repair and habitat structures technologies for manned missions that maximize the use of in situ resources to address the following agency topics:

1. Bioastronautics Critical Path Roadmap (BCPR) (Ref. 1) risks.

2. Strategic Technical Challenges defined in the Human \& Robotics Technology (H\&RT) Formulation Plan (Ref. 2).

ISFR Element supports the entire life cycle of the HSS program, enabling evolution of human space exploration by:

- Reducing downtime of failed components thereby decreasing risk to crew and system functionality and enhancing mission safety.

- Reducing crew exposure to environment by providing autonomous non-destructive evaluation technologies that are capable of identifying and confirming a failure and then validating the repair method was successful.

- Providing manufacturing and assembly technologies for habitats and other structures that incorporate in situ resources and produce autonomous, affordable, pre-positioned environments with radiation shielding features and protection from micrometeoroids and exhaust plumes.

- Reducing upmass/upvolume resource requirements for supply of spares and materials from Earth by utilizing in situ resources.

- Providing just-in-time fabrication of parts and tools to meet maintenance requirements of system failures via closed loop quality controlled solid freeform fabrication technologies, thereby reducing spare parts inventory.

- Providing just-in-time repair capability via soldering, patching, or adhesives.

To perform these functions, the ISFR Element supports a variety of equipment solutions including; handheld tools, portable machines, stationary or shop level machines, and mobile systems with capabilities for performing the mission functions. At the onset of deployment, the capabilities will be in line with small volume, small resource limitations of early flights, such as handheld tools and small parts makers or portable units. As the program reaches its full-scale deployment phase, capabilities will be continually enhanced to ensure that the comprehensive and large-scale needs of Mars habitation are supported. The primary objectives of the ISFR Element are:

- Provide fabrication and repair services commensurate with the needs of the Flight, Moon, and Mars mission operational plans.

- Provide fabrication and repair capability for unforeseen tools and parts.

- Provide construction of habitats, other structures based on in situ materials, and repair/maintenance capability.

- Provide inspection, testing, and troubleshooting service as an offshoot of fabrication inspection and test.

The ISFR Element is composed of the following sub-elements:

1. Fabrication Technologies sub-element: Includes parts and tools fabricated using additive, subtractive, conventional and hybrid technologies, using metals, ceramics and composites.

2. Repair and Non-Destructive Evaluation (NDE) Technologies sub-element: Includes mobile, shop, portable, and hand-held equipment.

3. Habitat/Structures sub-element: Structural element and radiation shielding element fabrication and repair capabilities, including berms, surface reactor shielding, supplemental protection for provisioned habitats, and full-scale in situ habitat development.

During the summer of 2005, the ISFR Element conducted a series of Technical Interchange Meetings (TIMs), one for each sub-element. The objective of this activity was to conduct a documented, in-depth and independent review 
of the ISFR technologies being presented, using a customer and peer review panel format. To that end, the TIM review groups (customer and peer) consisted of qualified individuals were independent of the ISFR teams performing the work. The TIMs provided an excellent opportunity for an exchange of ideas between the fields of expertise, opened new lines of communication, and expanded areas of understanding.

At the end of each TIM, the customer panel held a discussion to determine how well each sub-element addressed programmatic issues related to the chosen technologies, and whether or not the capability and development approach was what was needed for the Exploration Initiative. The peer panel met to determine technical issues related to the chosen technologies, and to substantiate the technology and development approach as presented at the TIM. The findings and recommendations from the customer and peer panels are discussed in detail later in this paper.

\section{Fabrication Technologies Sub-element Overview}

In 2005, the Fabrication Technologies Trade Study activity served to identify core technologies that will close gaps in current manufacturing technologies for space missions. They were identified by engineering judgment of factors such as fabrication speed limitations, geometric accuracy and tolerance assessment, and resource savings that might be realized by enhancement of current state of the art processing methods. The type of feedstock these technologies utilized was an important criterion in the evaluation process. Management and usage of bulk powders, sprayed powders, wires, filaments, tapes, stock shapes (plate, channels, ells, tees, etc.), and liquids, were evaluated for microgravity and hypo-gravity applications. In addition, the possibility of producing these feedstocks from in situ regolith or a recycle stream was also evaluated.

Most of these existing manufacturing technologies (ground based equipment) are heavy and voluminous, and require relatively large amounts of alternating current power. Development of units for spaceflight must be designed for weight and volume reduction and utilization of alternative power sources. In addition, the spaceflight systems must be ruggedized to survive launch and landing stresses, while providing long mean time between failures (MTBF) while in operational use.

While the Fabrication Technologies team received several helpful suggestions from the TIM Review Panels, the two primary recommendations were:

1. "Infiltrate" Fabrication Technologies into the front-end systems design activities.

2. Reduce initial scope to focus on highest priority materials - metals and ceramics.

Infiltrating Fabrication Technologies into the front-end systems design activities has both short term and long term ramifications. Even before the TIM, the Fabrication Technologies team was collaborating with the Propulsion Systems Combustion Design and Development Department at MSFC in an effort to fabricate a subset of complex combustion parts (i.e., interface plates, nozzles, manifolds, etc.). The Combustion Design team provided the 3D Computer Aided Design (CAD) files, which were imported into the existing manufacturing system software. Using Solid Free Form (SFF) Rapid Prototyping techniques, the production time for the development of these parts was greatly reduced. Once fabricated, these development articles were turned over to the Combustion Design team in order to be integrated into the hardware test complement proposed for an engine burn on Test Stand 115 at MSFC.

As a separate design collaboration activity, the Fabrication Technologies team worked with the Environmental Control and Life Support System (ECLSS) team to develop parts for both the Water Processing Assembly (WPA) and the Urine Processor Distillation Assembly.

Using rapid prototyping techniques, the Fabrication Team developed a ceramic (alumina) lattice structure and impregnated it with a catalyst. The monolithic lattice structures were fabricated using layer manufacturing technologies, and have been flow tested in the ECLSS bench top test system. Initial results indicated that a favorable reduction in pressure drop appears attainable in comparison to the existing packed pellet beds. Testing of additional lattice designs will be continued, with a complement of 4 units for optimization of the flow characteristics. If testing is successful, this structure may replace the existing ECLSS catalyst bed of pelletized clay and zeolite. See Figure 1 for a photograph of the ceramic lattice structure. 


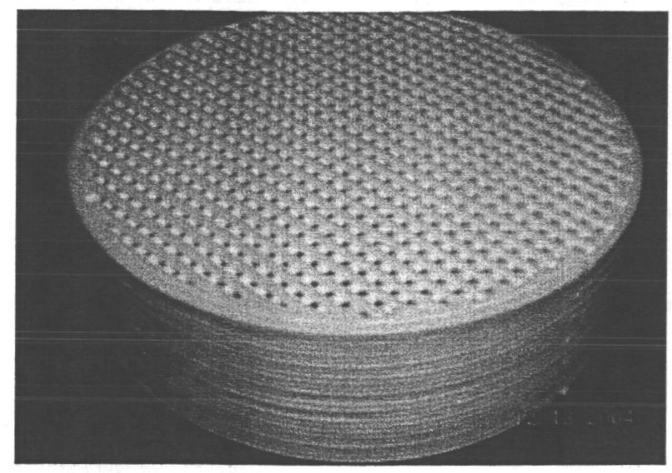

Figure 1 - Ceramic Lattice Structure

More detailed information on Fabrication Technologies activities is documented in the paper "Developing Fabrication Technologies to Provide On-Demand Manufacturing for Exploration of the Moon and Mars" (Ref. 3).

\section{Repair and NDE Technologies Sub-element Overview}

During 2005, the Repair \& NDE sub-element focused on the development of technologies for repairing other systems and evaluating the repair. The results of this work were presented at a Technology Interchange Meeting (TIM) in June 2005 with representatives of academia, industry and most NASA Centers present. The results of the TIM provided the direction to focus more heavily on developing an evaluation/qualification process (Ref. 4) which would be used to ensure that items fabricated in situ would be safe to use in situ. In response to the TIM findings, the Repair \& NDE team has worked extensively on developing an initial plan for qualifying items that were fabricated or repaired in situ.

The approach envisioned for qualifying/verifying of in situ fabrication or repair of parts is a combination of process verification to control general material properties, and additional Nondestructive Evaluation (NDE) technologies to verify additional requirements such as dimensions, surface finish, etc. While this approach deals with the qualification/verification of a specific part, the manufacturing process controlling the material characteristics can effectively be based on ground- and in-situ-based verification of the process; i.e., the process would be definable and repeatable, and parameters that determine product performance could be calibrated and controlled along with the feedstock material. Once a process is certified on the ground, the analog process must be certified for the in situ operation. This is envisioned as the most effective combination of test coupons produced in situ and returned for examination of any differences and process controls to monitor and control those differences. Factors that could affect the repeatability include environment, gravity level, age of the material, material purity (if obtained in situ), material reclamation, power levels, fabrication equipment de-calibration, and maintenance, and fidelity of remote inspection/measurement and NDE methods. Differences that could affect a part's performance must be resolved.

Once the qualification/verification requirements for an in situ fabricated or repaired part have been established, an approach to performing the program must be implemented. The goal for in situ would the same as for a conventional ground verification program for flight hardware. Emphasis would be placed on safety followed by function and performance. The in situ conditions present challenges that are equivalent in type to ground programs but are significantly different when assessed for feasibility. Constraints of up mass, equipment and personnel availability, and severity of environments add to the cost and complexity of the task. Table 1 provides a description of the challenges and the differences for in situ operations versus ground verification. This table is not an exhaustive list of differences but provides an example of the differences that must be addressed by in situ implementation. 
Table 1. Challenges of In Situ Qualification/Verification

\begin{tabular}{|c|c|c|}
\hline Challenge & Ground & In Situ \\
\hline Test Equipment Availability & $\begin{array}{l}\text { Extensive equipment and facilities available at } \\
\text { NASA centers, universities, and Industry }\end{array}$ & Limited to payload or habitat provisions \\
\hline Test and Quality Assurance Personnel & Extensive sources for personnel and expertise & $\begin{array}{l}\text { Limited to crew and data that can be } \\
\text { downlinked for evaluation }\end{array}$ \\
\hline Protection and Safety During Testing & $\begin{array}{l}\text { Ground activities can utilize extensive space for } \\
\text { isolation of hazardous testing to prevent hazards } \\
\text { to test personnel }\end{array}$ & $\begin{array}{l}\text { Space and isolation are limited by vehicle } \\
\text { and habitats }\end{array}$ \\
\hline Analysis Capabilities & Extensive sources for personnel and expertise & $\begin{array}{l}\text { No significant differences; however, longer } \\
\text { time delays for transmission of information } \\
\text { will occur due to transmission coverage. }\end{array}$ \\
\hline $\begin{array}{l}\text { Accessibility of Hardware for Functional } \\
\text { Evaluation }\end{array}$ & $\begin{array}{l}\text { Ground units or prototypes are usually available } \\
\text { for integrated checkout prior to installation into } \\
\text { the "flight" unit, reducing risk to critical } \\
\text { equipment. }\end{array}$ & $\begin{array}{l}\text { Integration into the "flight" hardware may } \\
\text { be the only means for functional evaluation } \\
\text { in the integrated assembly. }\end{array}$ \\
\hline
\end{tabular}

These differences lead to a conclusion that in order to avoid the limitations of in situ location, the program should make maximum use of preflight or ground support and terrestrial coupon testing (for in situ derived source materials) approaches to satisfy requirements. With this goal in mind, it is apparent that qualification offers more opportunity for implementing this approach than acceptance. Acceptance is greatly limited by the in situ location of the part (end item) to be verified.

As part of the qualification activity, the team is performing evaluation of NDE capabilities and to arrive at the optimum suite of technologies for advancement. Among the technology areas under consideration are thermal imaging techniques, laser techniques, electronics applications, x-ray techniques, acoustic, electromagnetic and chemical methods (see Figure 2). These will all be analyzed for their range of potential uses and the advantages of each, and specific technologies will be selected for maturation as necessary to meet ISFR goals.

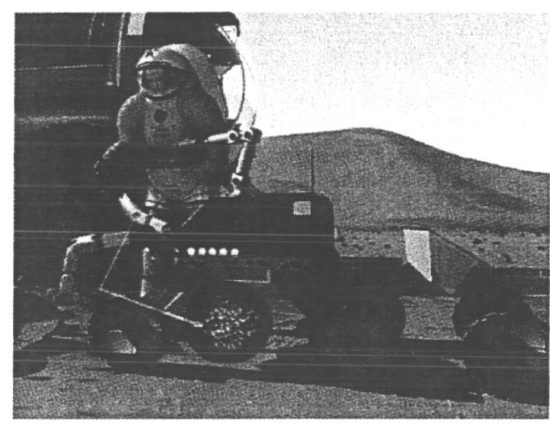

Figure 2 - Concept of crewperson using surface probe attached to camera to detect surface flaws in metals

\section{Habitat Structures Sub-element Overview}

During 2005, the Habitat/Structures sub-element has focused on the development of technologies associated with surface structures based primarily on in situ materials. After a comprehensive Technology Interchange Meeting (TIM) in June 2005 with representatives of academia, industry and most NASA Centers present, NASA Headquarters provided some direction to focus on earlier applications of these construction technologies including berms, surface-based reactor shielding, launch/landing pads, and unpressurized storage shelters/garages. Earlier demonstrations of relevant technologies on these applications will build confidence and processing skills required to construct full Class III (primarily in situ materials-based) habitats in the long term. The Robotic Lunar Exploration Program (RLEP) series of Lander missions also offer opportunities for demonstrations of key construction technologies. All of these structures must also be able to survive in the harsh environment of the lunar surface including temperature extremes, a hard vacuum, Galactic Cosmic Ray (GCR) and Solar Particle Event (SPE) radiation, solar wind exposure and constant micrometeorite bombardment.

Most of 2005 activities have focused on basic material development. Various organic and inorganic binders have been mixed with JSC-1 lunar regolith simulant, molded using a commercial blockmaker, cured, and tested for mechanical and thermal properties. Different coatings have been applied to these blocks to evaluate UV stability and 
radiation shielding effectiveness. A typical resin-coated block of JSC-1 and $\sim 30$ weight percent inorganic binder is shown in Figure 3 (Ref. 5).

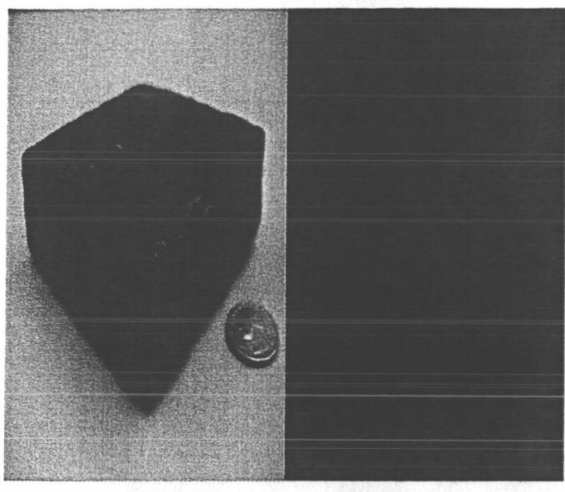

Figure 3 - Typical block made from JSC-1/inorganic binder

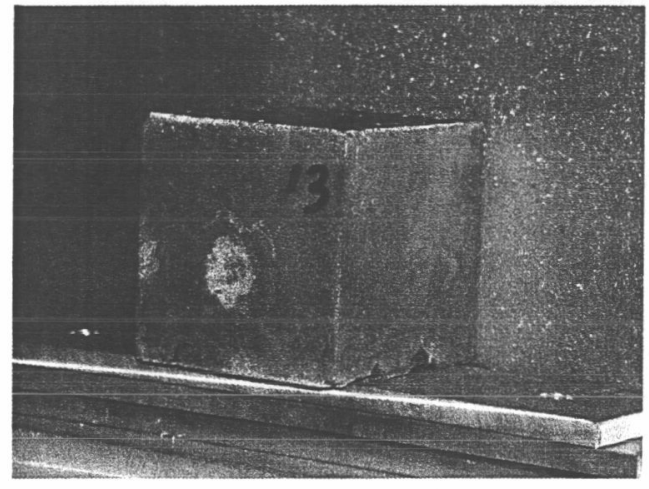

Figure 4 - JSC-1/sulfur "waterless concrete" block

Several waterless "concrete" formulations have been prepared, cast, characterized mechanically and thermally, and subjected to hyper-velocity impact tests to simulate direct micrometeorite hits, as shown in Figure 4 (Ref. 6). This block, composed of JSC-1 and 30\% weight percent sulfur and approximately 2" cube, was subjected to impact by a $1 \mathrm{~mm}$ aluminum sphere traveling at $\sim 10^{6} \mathrm{~km} / \mathrm{sec}$. The concrete held up remarkably well to a simulated, albeit slow, micrometeorite hit. Other basic material development efforts include identification of a fabric material that can be used to fabricate regolith bags for application as berms, reactor shielding etc. Figure 5 (Ref. 7) shows such a development test article under load testing.

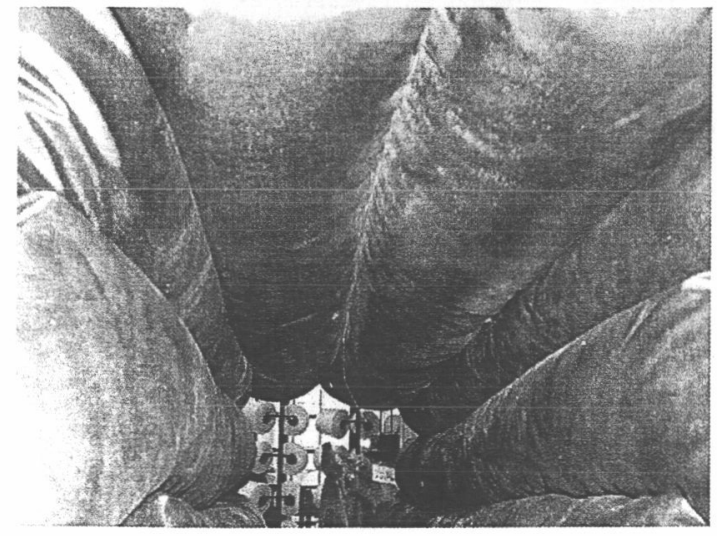

Figure 5 - Regolith bag structure demonstrating selfsupporting capability

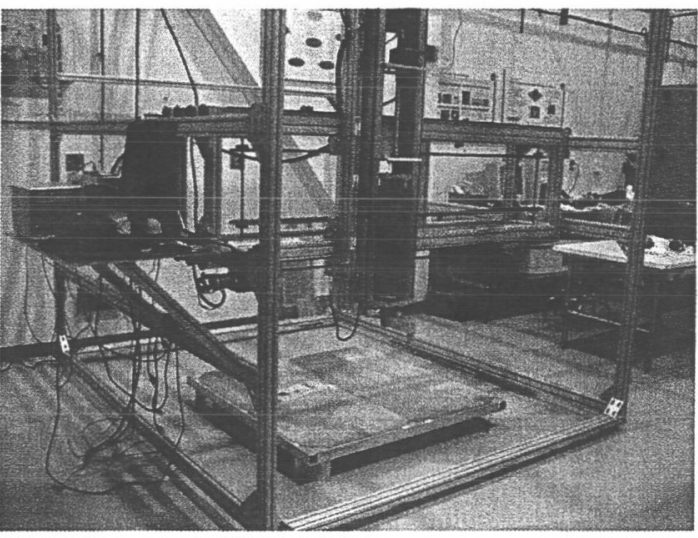

Figure 6 - Expanded Concrete Extrusion System at NASA/MSFC

From an integrated construction technology standpoint, major modifications have been made to MSFC's extruded concrete (also known as Contour Crafting) machine. As documented in the paper "Lunar Contour Crafting - A Novel Technique for ISRU-based Habitat Development" (Ref. 8), this system has been modified to expand its wall fabrication capabilities into three dimensions as shown in Figure 6.

For 2006, efforts will be focused on the earlier applications of these technologies, as mentioned previously. For example, application of the regolith bags shown in Figure 5 to berms for launch/landing debris ejecta protection will be analyzed. One possible configuration is shown in Figure 7 (Ref. 9). 


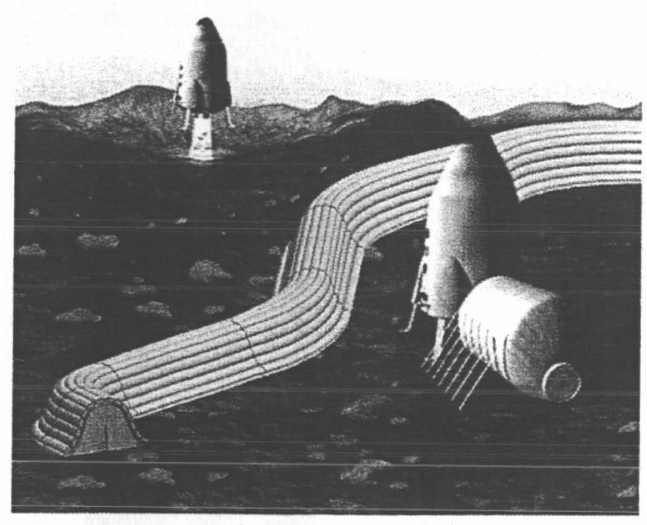

Figure 7 - Berm Concept Based on Regolith bag

\section{Summary}

While the ISFR Element was cancelled as a recommendation of the Exploration Systems Architecture Study (ESAS), these development challenges still exist for Exploration and will certainly resume in the future if we are to maintain a long-term human presence on the Moon and/or Mars. The value-added capabilities of the ISFR Element have been strongly established by the ISFR team. The ideas and work completed by the ISFR team provide a baseline for further development work which may be initiated in the future in support of Exploration initiatives.

\section{References}

1. Bioastronautics Critical Path Roadmap (BCPR), JSC 62577, Rev. E, April 2, 2004, also located at http://bioastroroadmap.nasa.gov/beta/index.jsp.

2. Human \& Robotics Technology (H\&RT) Formulation Plan, Version 5.1, September 13, 2004.

3. "Developing Fabrication Technologies to Provide On-Demand Manufacturing for Exploration of the Moon and Mars", M. Hammond, J. Good, S. Gilley, R. Howard, Paper AIAA-2006-0526, $44^{\text {th }}$ AIAA Aerospace Sciences Meeting \& Exhibit, Reno, NV, January 2006.

4. Unpublished work by Jim Kennedy and Fred Rose, Teledyne Brown Engineering, November 2005.

5. Unpublished work by Dr. Raj Kaul, NASA/MSFC/EM40, Nov.-Dec. 2005.

6. "Properties and Performance of Extraterrestrial "Concrete"," H. Toutanji, R. Grugel, B. Schrayshuen, Paper No. TBD, Habitation 2006 Conference, Orlando, FL, February 5-8, 2005. (accepted for publication)

7. Unpublished work by Gweneth Smithers, NASA/MSFC/EM40, Nov.-Dec. 2005.

8. "Lunar Contour Crafting - A Novel Technique for ISRU-based Habitat Development," Koshnevis, B., M.P. Bodiford, K.B. Burks, E. Ethridge, D. Tucker, W. Kim, H. Toutanji \& M.R. Fiske, Paper AIAA-2005-0538, Proceedings of the $43^{\text {rd }}$ AIAA Aerospace Sciences Meeting \& Exhibit, Reno, NV, January 2005.

9. Unpublished work by Regina Pope, Qualis Corporation, November 2005. 